DOI: $10.7242 / 1998-2097 / 2018.1 .6$

УДК 622.4

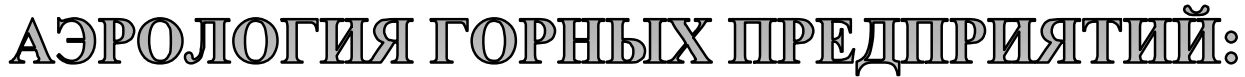

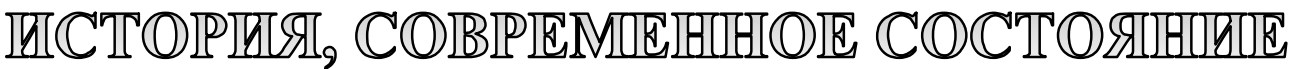

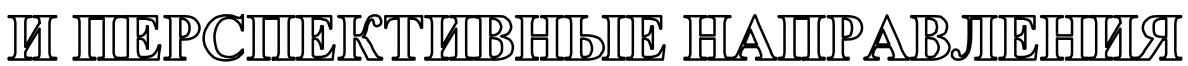

Л.Ю. Левин, Горный институт УрО РАН

А.В. Зайцев, Горный институт УрО РАН

Представлена история становления аэрологии горных предприятий в процессе развития добычи твердых полезных ископаемых. Описаны особенности современных шахт и рудников и актуальные задачи в области вентиляции, воздухоподготовки и кондиционирования воздуха на горнодобывающих предприятиях. Представлены современные подходы и инструменты для разработки эфффективных и ресурсосберегающих систем рудничной вентиляции. Приведены фрактические результаты внедрения новых технологий и технических средств вентиляции горнодобывающих предприятий. Отмечены перспективные направления исследований и разработок, а также необходимость совершенствования нормативнометодической базы в области рудничной аэрологии.

Ключевые слова: горное предприятие, полезные ископаемые, промышленная безопасность, рудничная аэрология, горная теплофизика, вентиляторы, программное обеспечение, АэроСеть, автоматизация, мониторинг, энергосбережение.

Аэрология горных предприятий - отрасль горной науки, изучающая свойства атмосферы шахт и рудников, законы движения воздуха, переноса газообразных примесей, пыли и тепла в горных выработках и прилегающем к ним массиве горных пород. Эта область знаний базируется на законах общей аэромеханики и термодинамики, использует применяемые в них методы исследований и наблюдений состояния рудничной атмосферы $[1,8]$.

Воздушная оболочка Земли, называемая атмосферой, - это среда жизнедеятельности человека. Ее газовый состав на земной поверхности характеризуется большим постоянством вследствие высокой подвижности воздуха и взаимной компенсации процессов выделения и поглощения газов. Поэтому на земной по- верхности не возникает проблемы искусственного поддержания требуемого для жизнедеятельности человека газового состава воздуха. Однако в помещениях, отделенных от земной поверхности частично или полностью, действие указанных факторов ослабевает или прекращается вовсе, а изменения в них состава воздуха вследствие поглощения или выделения газов при протекании производственных процессов (или из-за присутствия в них людей) вызывают необходимость вентиляции, иными словами, обновления воздуха. Суть вентиляции помещения и состоит в подаче и распределении чистого (свежего) воздуха, а также в удалении загрязненного воздуха. Подземные выработки шахт и рудников вследствие почти полной их изоляции от земной поверхно- 
сти, наличия в них процессов поглощения кислорода и выделения газов (чуждых земной атмосфере), повышения температуры воздуха, отсутствия солнечного света (биологическое и гигиеническое действие которого велико) особо нуждаются в организации вентиляции. Без этого нахождение рабочих в горных выработках и добыча полезных ископаемых невозможна. Таким образом, шахта - это единый организм, в жизни которого вентиляция играет такую же роль, как дыхание для человека.

С необходимостью вентиляции подземных выработок люди столкнулись давно. Так, остатки римских рудников в Рио-Тинто в Испании, действовавших более 2000 лет назад, свидетельствуют о том, что уже в то время более длинные штольни снабжались вентиляционными шурфами. Способы создания естественной тяги в шахтах описаны римским писателем Плинием старшим в «Естественной истории (І век н.э.). Сведения о вентиляции подземных выработок приводит писатель Георгий Агрикола в «Горном и заводском деле» (XVI в.). В тот период технические возможности вентиляции были весьма ограничены. Движение воздуха в шахтах происходило в основном под действием разности его плотностей (естественная тяга) или за счет энергии ветра, а средствами интенсификации вентиляции были меха, костры или печи, подогревавшие воздух, в результате чего усиливалось его естественное движение. Одним из первых научных исследований в области рудничной аэрологии, положившим начало ее развитию как науки, явился трактат М.В. Ломоносова «О вольном движении воздуха в рудниках примеченном» (1742 г.), в котором впервые была объяснена природа естественной тяги воздуха в шахтах и открыты законы ее проявления. В развитии рудничной аэрологии как науки деятельное участие приняли русские ученые.

Однако несмотря на появление понимания аэрологических процессов, развитие горных работ сдерживали ограничен- ные технические возможности вентиляционного оборудования. Преодолеть этот барьер позволил механический вентилятор, изобретенный в 1832 г. в России генерал-лейтенантом корпуса горных инженеров А.А. Саблуковым. Установка на шахтах механических вентиляторов позволила на значительный период снять ограничения на расширение масштабов горных работ по фактору вентиляции. Появление в шахтах выделений горючих и ядовитых газов потребовало дальнейшей интенсификации вентиляции (случаи вспышек и взрывов метана в шахтах известны горнякам с XVI века, в России впервые такой случай имел место в 1878 году на угольной шахте в Донбассе).

В XIX веке начинается изучение свойств шахтной атмосферы на высоком научном уровне. Были выполнены многочисленные исследования (аэродинамического сопротивления выработок, состава шахтного воздуха и свойств выделяющихся в горные выработки газов, температуры горных пород и воздуха в горных выработках и влажности последнего), созданы приборы для соответствующих измерений. Из ученых этого периода следует отметить Узатиса (в России), Шандорффа (в Германии), Вуда (в Великобритании), изучавших состав шахтной атмосферы, Жирара, Добюиссона, Мюрга, Пти (во Франции) и Аткинсона (в Великобритании), исследовавших аэродинамическое сопротивление горных выработок. В начале XX века начинается интенсивное развитие рудничной аэрологии в России. Этот период открывается фундаментальной работой А.А. Скочинского «Рудничный воздух и основной закон движения его по выработкам» (1904 г.), в которой обобщены многочисленные исследования состава и свойств шахтного воздуха и впервые применено к его движение известное уравнение Бернулли.

Деятельность А.А. Скочинского (1874-1960), профессора Петербургского, затем Московского горных институтов занимает особое место в развитии рудничной аэро- и газодинамике, шахтной 
атмосфере и метода ее контроля, внезапным выбросам угля и газа, шахтным пожарам, рудничной пыли. Им совместно с профессором ЛГИ В.Б. Комаровым написан учебник «Рудничная вентиляция», выдержавший три издания [8]. За него авторам была присуждена Государственная премия СССР. А.А. Скочинский является основателем отечественной школы рудничной аэрологии. В 1930 году в МГИ им создана кафедра рудничной вентиляции, которую он возглавлял почти четверть века. В 1938 году по инициативе и при участии А.А. Скочинского создается институт Горного дела АН СССР. До конца своих дней А.А. Скочинский - директор этого института и руководитель отделения рудничной аэрологии.

С течением времени, несмотря на достигнутые успехи, из-за увеличивающихся глубины горных работ, нагрузок на забои шахт и включение в работу множества электрического и дизельного оборудования, в горных выработках происходит выделение большого количества тепла, горючих и ядовитых газов. Бороться с такими количествами газа традиционными способами (разбавлением газа воздухом и выносом из шахты вентиляционной струей) во многих случаях оказывается уже невозможным из-за необходимости подачи в шахты чрезвычайно большого количества воздуха и превышения допустимых скоростей его движения по выработкам. Кроме того, с углублением горных работ повышается температура воздуха в горных выработках, что требует разработки специальных средств воздухоохлаждения, без которых дальнейшее углубление и развитие горных работ становится невозможным [6].

Современные условия добычи полезных ископаемых, определяемые необходимостью поддержания и увеличения производственных мощностей, характеризуются все более жесткими значениями: увеличиваются глубина разработки (более одного километра), площади шахтных полей (свыше 100 квадратных километров), снижается содержание полезных компонентов в руде. Из-за изменения па- раметров значительно возрастают капитальные затраты на строительство объектов производства. Необходимо увеличивать объемы добычи для компенсации снижения качества руды. Ухудшаются условия труда горнорабочих. Сложнее организовать проветривание и доставку воздуха на удаленные горные участки, это приводит к увеличению аварийных ситуаций. Также намного труднее проводить мероприятия по их локализации и ликвидации. Очевидно, что такие условия вынуждают разрабатывать новые технологии и технические средства для обеспечения безопасности ведения горных работ и высокопроизводительной добычи полезных ископаемых в сложных горнотехнических условиях.

Кроме того, системы вентиляции современных шахт, как объекты исследования, являются очень сложными [2]. Суммарная протяженность выработок, по которым движется воздух, в современных шахтах может достигать 120 километров. Пример топологии вентиляционной сети рудника «Комсомольский» ЗФ ПАО «ГМК «Норильский никель», на котором ведется добыча медно-никелевых руд, приведена на рис. 1.

Для вентиляции таких крупных шахт подается до $1500 \mathrm{~m}^{3} / \mathrm{c}$ воздуха. Наиболее крупные вентиляторные установки имеют рабочие колеса диаметром 5 м, а приводы - мощностью до 10 МВт. Пример агрегата шахтной вентиляторной установки приведен на рис. 2. Они могут формировать напор до 10000 Па при расходе воздуха до $600 \mathrm{~m}^{3} / \mathrm{c}$. Дополнительно работающие системы подогрева и кондиционирования воздуха на горных предприятиях имеют мощности десятки мегаватт. Поэтому суммарные затраты на подготовку, подачу и транспортировку воздуха в горных выработках могут достигать 70\% в структуре затрат добычи полезного ископаемого. Поэтому качество системы вентиляции рудника или шахты определяет общий результат работы предприятия не только в сфере безопасности, но и в экономике. 


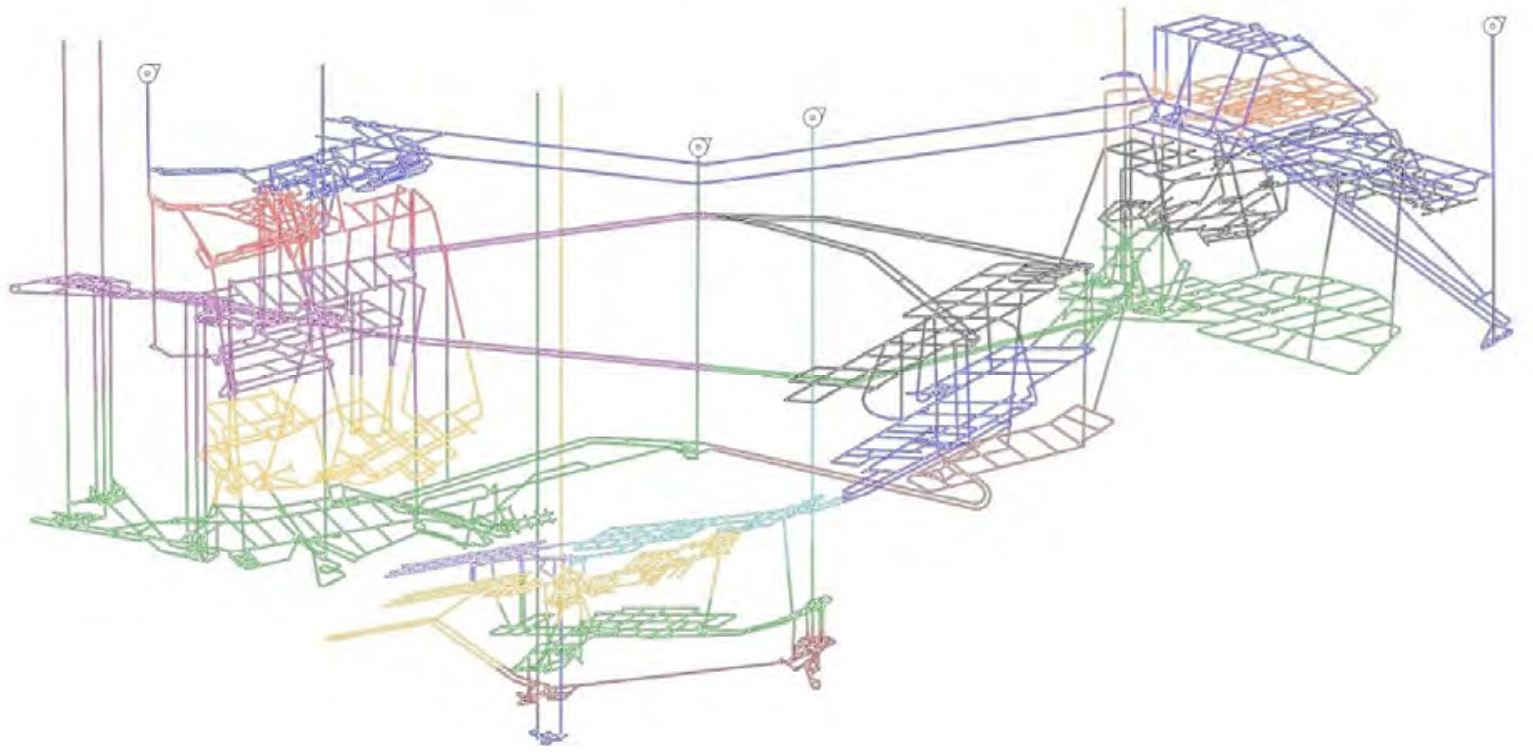

Рис. 1. Топология рудничной вентиляционной сети рудника «Комсомольский» ЗФ ПАО «ГМК «Норильский никель»

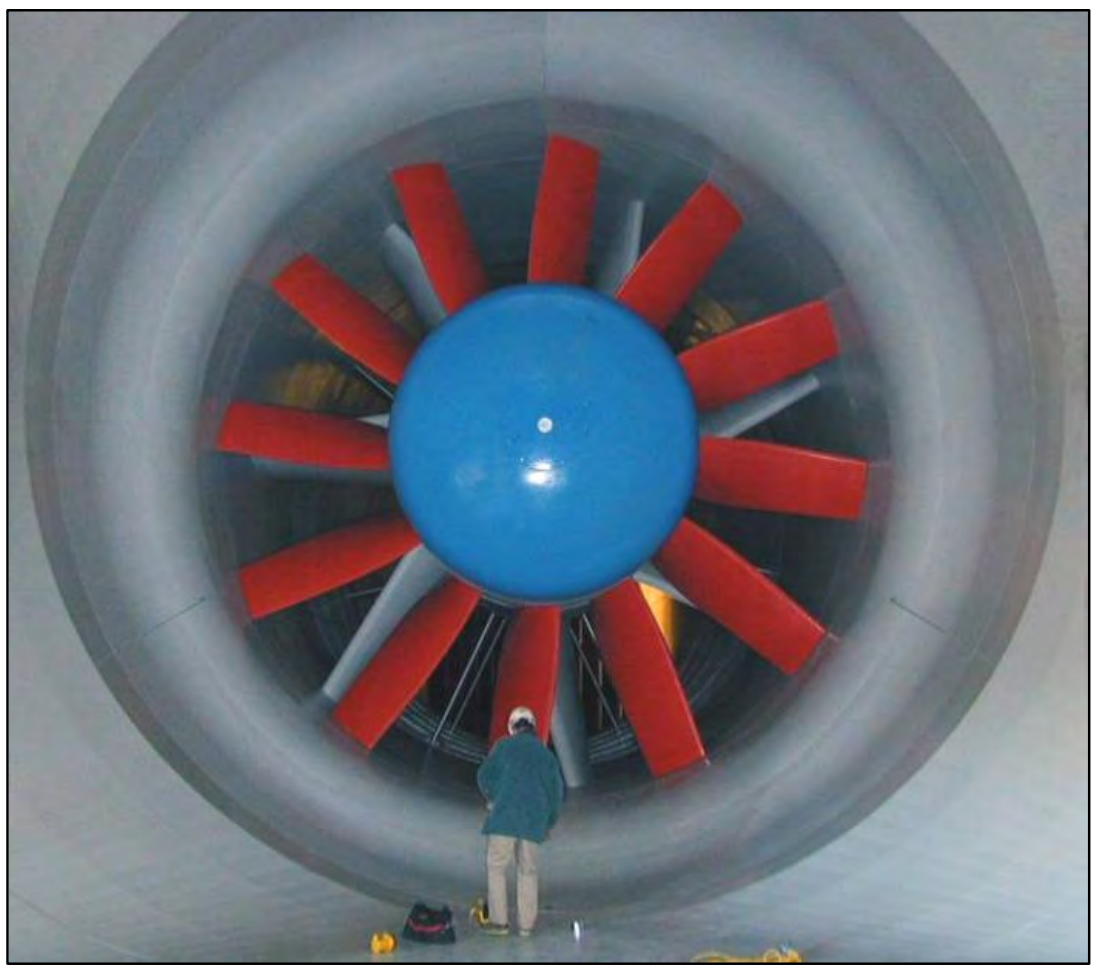

Рис. 2. Агрегат шахтной вентиляторной установки

В условиях современной рыночной экономики зачастую стоит задача обеспечения максимальных объемов добычи, и на сегодняшний день на многих шахтах процессы вентиляции определяют нагрузки на очистные забои и темпы проведения выработок, лимитируя возможность наращивать объемы добычи. Все это сопровождается еще одной особенностью горного производства - постоянно меняющимися условиями работ. Технические службы предприятия должны иметь технологии прогнозирования этих изменений и в сжатые сроки принимать правильные решения по обеспечению рабочих мест требуемым количеством свежего воздуха и организации эффективного удаления вредных газов и пыли. А в усло- 
виях возникновения таких аварийных ситуаций, как подземные пожары, взрывы, внезапные выбросы газа, принятый вентиляционный режим должен обеспечить спасение застигнутых аварией в шахте людей и быстрейшую ликвидацию аварийной ситуации.

Таким образом, современные реалии горного производства определяют высокую актуальность разработки новых технологий рудничной вентиляции, что позволяет обеспечивать безопасность ведения горных работ во все более сложных условиях, снижать затраты на добычу полезных ископаемых и, в конечном счете, повысить конкурентоспособность горного производства в целом [5].

Решение этих задач возможно только при работе на стыке фундаментальной и прикладной наук, когда разработка эффективных технических решений базируется на исследовании протекания физических процессов в постоянно изменяющихся горно-геологических условиях. Кроме этого, специалисты по рудничной аэрологии занимаются непосредственным сопровождением внедрения разработанных технических решений и помогают обеспечить выполнение правил безопасности, повысить надежность работы систем вентиляции в штатном и аварийном режимах, сделать работу служб вентиляции горных предприятий более удобной.

С учетом сложности изучаемых объектов требуются специальные программные инструменты. В ГИ УрО РАН разработан специальный аналитический комплекс «АэроСеть», который первоначально предназначался для вариантного моделирования ситуаций воздухо-, тепло- и газораспределения в сети горных выработок. На этом первоначальном периоде «АэроСеть» представляла собой программно-вычислительный комплекс как сочетание пакета программ с базой данных и методикой решения задач в области рудничной вентиляции и горной теплофизики для разработки проектных технических решений.
Но далее стало очевидно, что важнейшей частью успешной деятельности горнодобывающих, проектных и научно-исследовательских организаций для разработки оптимальных решений при добыче полезных ископаемых является работа именно с актуальной информацией.

Таким образом, потребовалось разработать интерактивную систему хранения и обработки данных, отчетности, обеспечить приток информации из разнообразных источников, которыми могут быть датчики, установленные в горных выработках, или специалисты горного предприятия, проектной или научно-исследовательской организации.

В итоге получилось, что из программно-вычислительного комплекса разработка преобразовалась в полноценный аналитический комплекс «АэроСеть» [7], представляющий целую платформу для решения задач обеспечения безопасных условий труда в горных выработках (рис. 3).

На сегодняшний день аналитический комплекс представляет собой некий конструктор, его модули позволяют собирать, обрабатывать данные и на основе математического моделирования осуществлять многовариантное прогнозирование ситуации, рассчитывать ресурсы, необходимые для достижения цели, оптимизировать их. Его функционал рассчитан на широкий круг задач. Это и инструмент для разработки проектных решений, и инструмент для работников предприятия, который помогает им принимать решения, вести необходимую отчетную документацию, быть справочником необходимой информации.

Развитие комплекса «АэроСеть» тесно связано с основным современным направлением развития современной рудничной аэрологии - разработкой автоматизированных систем мониторинга и управления шахтной вентиляцией $[3,4]$. Оно базируется на интеграции современных достижений в области автоматизации и информационных технологий с рудничной вентиляцией и горной теплофизикой. 


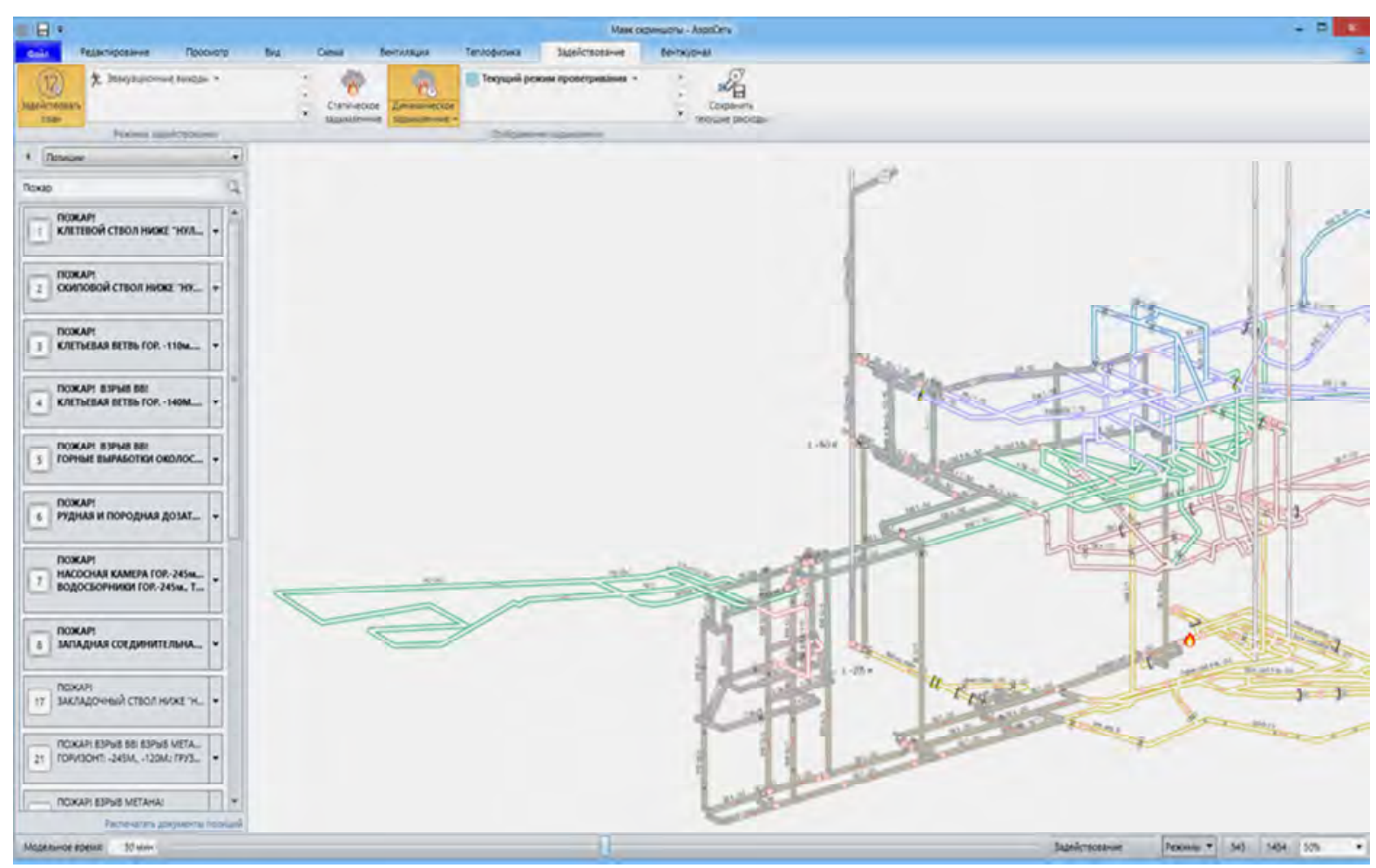

Рис. 3. Прогнозирование задымления горных выработок при пожаре спустя 30 минут в интерфейсе программы «АэроСеть»

Если рассуждать об актуальности такой системы, то можно отметить, что контроль и своевременное управление вентиляцией горных выработок - это залог для создания безопасных и комфортных условий труда в подземных рабочих зонах. Это всегда было важнейшей эксплуатационной задачей при разработке месторождений полезных ископаемых. И все традиционные мероприятия по контролю проветривания горных выработок можно разделить на две большие группы - периодические и оперативные. К первой относятся ручные инструментальные измерения расхода воздуха, его микроклиматических параметров и концентрации горючих и ядовитых примесей. На качество воздуха при движении по горным выработкам влияют различные факторы: изменение аэродинамического сопротивления горных выработок, особенности вентиляционных сооружений, суточные и сезонные колебания естественной тяги. Все это не позволяет использовать периодический контроль параметров рудничной вентиляции для оценки со- стояния системы вентиляции в реальном времени и, тем более, прогноза развития аварийного воздухораспределения.

Ко второй группе относится оперативный мониторинг параметров проветривания горных выработок. Это автоматические системы раннего обнаружения пожаров (АСОП) и системы аэрогазодинамического контроля (АГК) на угольных шахтах. Их установка обязательна для обеспечения безопасности, в соответствии с указаниями Ростехнадзора России.

Системы вентиляции современных шахт и рудников очень сложные, это затрудняет обеспечение измерительной аппаратурой замерных пунктов, необходимых для оперативного контроля. Практика показывает, что выход из строя датчиков случается довольно часто. Это приводит к полной потере контроля параметров проветривания в выработке (в которой датчик установлен) и снижению надежности системы мониторинга в целом. Как результат, неправильная оценка текущей ситуации проветривания и ошибки в прогнозировании воздухораспределения, в 
том числе в аварийных ситуациях.

Задача системы автоматизированного мониторинга воздухораспределения - это получение полного объема информации о воздухораспределении в вентиляционной сети при использовании минимального количества датчиков, что позволяет устранить недостатки традиционных способов контроля. Для этого разработан метод расчета воздухораспределения, позволяющий делать прогноз на основании математической модели вентиляционной сети [3].

Но кроме мониторинга и контроля вентиляции, необходимо внедрение в шахтах технологий оперативного автоматического управления воздухораспределением, основанных на совместном управлении вентиляторными установками и автоматическими регуляторами. Такой комплекс позволяет обеспечить доставку свежего воздуха всем потребителям рудника в требуемом количестве, при этом полностью в автоматическом режиме и при минимальных затратах электроэнергии. Данная система включает в себя комплекс математических алгоритмов, программных средств и практических методов построения оптимальных систем автоматического управления проветриванием подземных рудников. На рис. 4 при- ведено изображение автоматической вентиляционной двери, установленной в руднике 3 РУ ОАО «Беларуськалий», являющейся одним из технических средств описанного комплекса.

Это новая для мировой практики рудничной вентиляции задача - мониторинг и управление распределением воздушных потоков в реальном времени с возможностью прогноза при возникновении нештатных ситуаций. Такие системы позволяют осуществлять оперативное автоматическое управление воздухораспределением в вентиляционной сети. Аналогов им нет ни в России, ни за рубежом.

Однако решение задачи оперативного контроля и управления вентиляцией подземных рудников является только началом и обладает огромным потенциалом к внедрению. Кроме того, на современном этапе развития перед нами стоит ряд задач, которые еще предстоит решить.

Во-первых, мы планируем активное сотрудничество с горными предприятиями. Ведь наибольшее удовлетворение от работы человек получает, когда видит живое воплощение своих идей, исследований, разработок. Как показывает практика, каждое новое горное предприятие требует учета своих особенностей, что

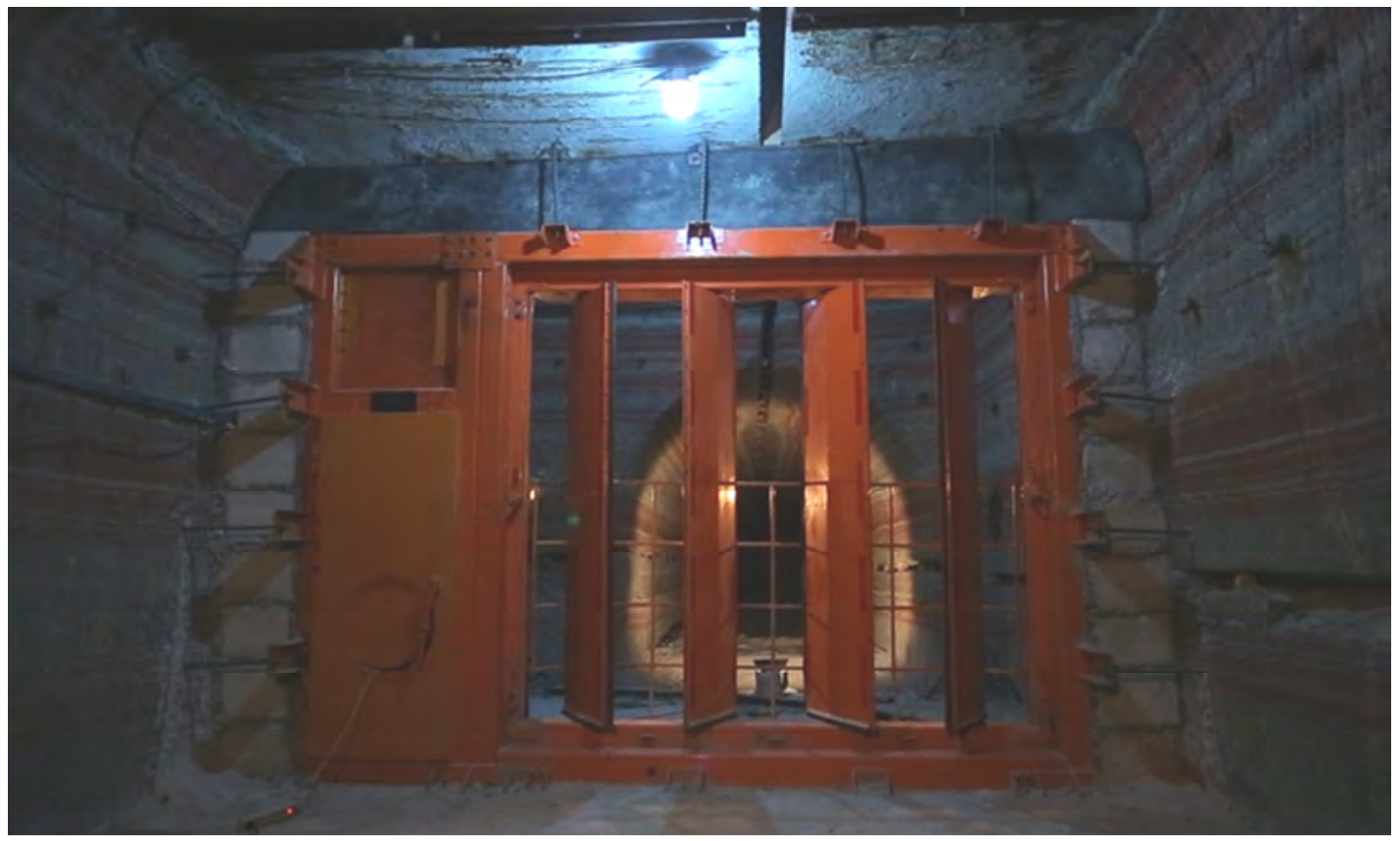

Рис. 4. Регулирование расхода воздуха по выработке с помошью автоматической вентиляционной двери 
позволяет совершенствовать разработанные технологии.

На сегодняшний день мы уже активно сотрудничаем с горными предприятиями страны и ближнего зарубежья. Наши заказчики - как крупнейшие, так и небольшие горнодобывающие предприятия. Это ПАО «Уралкалий», ОАО «Беларуськалий», ПАО «ГМК «Норильский никель», группа предприятий «Акрон», ООО «ЕвроХим», АК «Алроса», ОАО «Руссоль».

Внедрение инноваций - это долгий путь, который может затянуться на годы, поэтому всем участникам процесса необходимо иметь большое терпение. Необходимо находиться в постоянном контакте с горными предприятиями, узнавать их проблемы и помогать решать их, убеждать в необходимости и целесообразности внедрения новых технологий. Часто приходится сталкиваться с нежеланием специалистов (как на предприятиях, так и в проектных институтах) развиваться и осваивать новые технологии, менять подходы к производству. Руководители, инвесторы и собственники не спешат вкладывать деньги в уникальные, несерийные проекты. А каждое горное предприятие уникально. Даже системы разработки на рудниках одного месторождения могут сильно различаться, иметь свою специфику, особые горно-геологические условия. Поэтому максимальный экономический эффект приносят уникальные, созданные под конкретные задачи проекты.

Пример в этой сфере - Республика Беларусь. Наибольшее количество эффективных ресурсосберегающих технологий вентиляции рудников внедрено именно там. Это стало возможно благодаря трем важным факторам. Во-первых, в 2007 году Президент Республики Беларусь издал директиву, согласно которой предприятия должны обеспечить снижение энер- гоемкости валового внутреннего продукта не менее чем на 31 процент к 2010-му, не менее чем на 50 процентов - к 2015-му, не менее чем на 60 процентов к 2020 году (по сравнению с уровнем 2005 г.). Во-вторых, органы технического регулирования Беларуси открыты инновациям, готовы обсуждать новые технологии, дают им «зеленый свет». В-третьих, руководители горных предприятий Беларуси заинтересованы в повышении эффективности предприятия и конкурентоспособности своей продукции.

На рудниках ОАО «Беларуськалий» с участием ГИ УрО РАН внедрен ряд энергосберегающих мероприятий, благодаря этому только на одном руднике энергопотребление вентилятора главного проветривания снизилось с 4,1 МВт до 0,9 МВт, то есть более чем в 4 раза. А экономический эффект измеряется десятками миллионов евро.

Возможно, нынешние сложные экономические условия подтолкнут собственников и руководителей горнодобывающих предприятий к сотрудничеству с наукой и внедрению инновационных разработок российских ученых. В этом процессе является важным, чтобы регулирующие и контролирующие структуры, разрабатывающие правила безопасности для ведения горных работ, с вниманием относились к новым разработкам в области обеспечения безопасности ведения горных работ и рационального недропользования.

Решение еще одной важной задачи тесной интеграции науки, проектирования и производства - это привлечение к совместной работе со специалистами научных организаций грамотных маркетологов, активных менеджеров для продвижения и реализации инновационных идей и проектов.

\section{Библиографический список}

1. Аэрология горных предприятий: учеб. для вузов / А.С. Бурчаков, И.И. Медведев, Л.А. Пучков, К.З. Ушаков. - М: Недра, 1987. - 421 с.

2. Казаков Б.П. Современные состояние и направления развития исследований в рудничной аэрологии // Стратегия и процессы освоения георесурсов: Материалы ежегодной научной сессии ГИ УрО РАН по результатам НИР в 2009 г. - Пермь, ГИ УрО РАН. - 2010. - С. 180-182. 
3. Кормщиков Д.С. Разработка систем аэрогазодинамической безопасности подземных рудников // Стратегия и процессы освоения георесурсов: Материалы ежегодной научной сессии ГИ УрО РАН по результатам НИР в 20015 г. - Пермь, ГИ УрО РАН. - 2015. - С. 66-69.

4. Круглов Ю.В. Теоретические и технологические основы построения систем оптимального управления проветриванием подземных рудников: дис. ... д-ра техн. наук: 25.00.20. - Пермь, ГИ УрО РАН, 2012. $-340 \mathrm{c}$.

5. Левин Л.Ю. Исследование динамики воздушных потоков вентиляционных сетей и разработка безопасных, энергосберегающих систем вентиляции рудников // Стратегия и процессы освоения георесурсов: Материалы ежегодной научной сессии ГИ УрО РАН по результатам НИР в 20011 г. Пермь, ГИ УрО РАН. - 2011. - С. 233-234.

6. Особенности формирования микроклиматических условий в горных выработках глубоких рудников / В.Н. Карелин, А.В. Кравченко, Л.Ю. Левин, Б.П. Казаков, А.В. Зайчев // Горный журнал. - 2013. № 6. - C. $65-68$.

7. Свидетельство № 2015610589 об официальной регистрации программы для ЭВМ «Аналитический комплекс «АэроСеть» / А.В. Зайцев, Б.П. Казаков, А.В. Кашников, Ю.В. Круглов, Л.Ю. Левин, П.С. Мальков, А.В. Шалимов. - http://aeroset.net/.

8. Скочинский А.А., Комаров В.Б. Рудничная вентиляция: учеб. - М.: Углетехиздат, 1959. - 632 с.

\title{
MINE VENTILATION: HISTORY, STATE-OF-THE-ART AND PROSPECTIVE LINES OF DEVELOPMENT
}

\author{
L.Yu. Levin, A.V. Zaitsev \\ Mining Institute UB RAS
}

The history of the mine ventilation formation is presented in the process of evolution of mining industry in Russia and the CIS countries. The features of modern mines and actual mine ventilation and conditioning problems are described. Modern approaches and tools for developing efficient and resource-saving mine ventilation systems are presented. Actual results of the implementation of new ventilation technologies are shown. Prospective lines of research and development are noted, as well as arguments for the necessity to improve the regulatory documents in the field of mine ventilation.

Keywords: mining, minerals, industrial safety, mine aerology, mining thermal physics, fans, software, AeroSet, automation, monitoring, energy saving.

\section{Сведения об авторах}

Левин Лев Юрьевич, доктор технических наук, заместитель директора по научной работе, Горный институт УрО РАН - филиал Пермского федерального исследовательского центра УрО РАН (ГИ УрО РАН), 614007, г. Пермь, ул. Сибирская, 78А; e-mail: aerolog_lev@mail.ru

Зайцев Артем Вячеславович, кандидат технических наук, заведующий сектором математического моделирования и информационных технологий отдела аэрологии и теплофизики, ГИ УрО РАН; e-mail: aerolog.artem@gmail.com 